\title{
Trabajadores y lucha por el poder político en el gobierno de Carranza. Los orígenes de la acción múltiple (1917-1920)
}

\section{Nicolás Cárdenas García}

\section{Introducción}

Los inicios de la relación del movimiento obrero con la Revolución mexicana se ubican justo en el momento en que se dirime. cuál de las fuerzas participantes habría de imponerse sobre las demás, y en consecuencia, cuál de ellas tendría la posibilidad de concretar en el nivel nacional su proyecto político. Si en algún momento pareció que las fuerzas en lucha contra la usurpación huertista constituían un conglomerado homogéneo, a fines de 1914 y principios de 1915 era evidente que en su interior se libraba una enconada lucha de clases. De hecho, la Convención es el lugar en que afloran las enormes diferencias entre los ejércitos campesinos de Villa y Zapata, y las concepciones liberal-decimonónicas de Carranza y sus allegados. Para unos era necesario realizar profundos cambios en la estructura social, sobre todo en lo referente a la propiedad de la tierra, así como estructurar un gobierno democrático popular, mientras que para los segúndos, el problema de la revolución se reducía a términos de legalidad constitucional.

Sin embargo, dentro del propio constitucionalismo existía una corriente de jefes revolucionarios provenientes de sectores medios que reconocian la necesidad de impulsar reformas sociales como fundamento de la modernización capitalista del país, a la vez que como instrumento para desarmar ideológicamente a sus enemigos convencionistas. Entre éstos, destacaron por su influencia los dirigentes norteños, en particular los sonorenses. Formados en una cultura política fuertemente pragmática, en el respeto a las instituciones estatales, en la agricultura moderna, con una ideología empresarial muy arraigada, contaban con un bagaje que les permitía enfrentar con ventaja la lucha por el poder político nacional.

Por otro lado, estos jefes también reconocian las potencialidades de los obreros y campesinos, reveladas de manera drámatica en la huelga de Cananea y en la secular resistencia yaqui a abandonar sus fértiles tierras.

Ese conjunto de caracteristicas dio como resultado una práctica mediatizadora frente a las clases subalternas. Se reconocían sus demandas y peso político, pero se buscaría asimilarlos al proyecto modernizador capitalista, como una de sus fuentes fundamentales de conservación y sustento.

En el caso especifico del movimiento obrero, esta política se llevó a cabo en un proceso más o menos largo y contradictorio, cuyo primer momento fue la firma del pacto entre la Casa del Obrero Mundial (COM) y el constitucionalismo, el 17 de febrero 
de 1915. Como resultado del pacto, se formaron los batallonés rojos, que, a las órdenes de Obregón, combatieron a los villistas. Paradójicainente, un sector de los obreros cooperó a la derrota de la clase que, en teoria, era su aliado potencial: el campesinado pobre.

El compromiso, adquirido de esa manera, de luchar por la causa del constitucionalismo a cambio de promesas de reformas legales favorables a los trabajadores, mostraba la debilidad organizativa e ideológica del movimiento obrero de la época, que lo llevaba a aceptar una alianza dirigida por los sectores liberales de la burguesia revolucionaria, tratando de incorporar sus demandas al programa de la revolución. ${ }^{1}$ Ello representaba el primer paso de abandono de la línea de acción directa preconizada hasta entonces como estrategia de lucha obrera, aun cuando sólo una parte de la cOM aceptó los términos de la alianza. La acción directa implicaba el enfrentamiento con la clase patronal y el Estado, mientras que el Pacto involucraba a un sector obrero con un proyecto ajeno, sirviéndole de base social. A pesar de ello, esto no representó el triunfo de la estrategia reformista de acción múltiple, ya que ésta suponía la apertura de diversos frentes de lucha, particularmente en el terreno de la política, es decir, en el de la disputa por la dirección del Estado y sus aparatos, además de la constitución de las estructuras organizativas correspondientes.

En todo caso, poco después se reveló la fragilidad de esa primera alianza. Carranza no veía con buenos ojos las posibilidades que ofrecia para el fortalecimiento organizativo de los obreros, y mucho menos las pretensiones que empezaron a manifestar en 1916 los trabajadores de Veracruz, Tampico y el Distrito Federal, en demanda de mejores salarios y su pago en pesos de plata, ya que la crisis monetaria, la inflación, la carestía, y la devaluación, del papel moneda emitido por los constitucionalistas, habian alcanzado niveles graves y golpeaban severamente a la economía de los trabajadores. Ante la negativa a atender sus peticiones, la COM decidió declarar una huelga general en julio de 1916. El primer acto fue ejecutado por los electricistas, quienes cortaron el suministro de luz a la capital del país.

La respuesta del primer jefe, Venustiano Carranza, fue inmediata y definitiva; se implantó la ley marcial, fueron aprehendidos los miembros del Comité de Huelga y otros dirigentes sindicales, y finalmente revivió la ley decretada por Juárez en 1862, que condenaba a muerte a quienes colaboraran con los invasores franceses. En este caso, hacía sujeto de dicha pena a todo aquel que participara en la huelga o en reuniones celebradas para discutir su realización, califícándolos de traidores a la patria. El sustento argumental de tal medida era que no podia permitirse, en las difíciles circunstancias que vivía el país, la suspensión de los servicios públicos.

\footnotetext{
1 Véase Rosendo Salazar, Las Pugnas de la Gleba (los albores del movimiento obrero mexicano), México, PRI, 1972, t. I., p. 75-82; Marjorie Ruth Clark, La organización obrera en México, Trad. Isabel Vericat, México, Ed. Era, 2a. ed., 1981, p. 30-35: José Ma. Calderón, Génesis del Presidencialismo en México, México, Ed. El Caballito, 3a. ed., 1980, p. 74-77; Barry Carr, El movimiento obrero y la política en México, 1910-1929. Trad. Roberto Gómez Ciriza, México, Ed. Era,1981, p. 66-68.
} 
Durante el conflicto, Obregón, entonces secretario de Guerra, se constituyó una vez más en el mediador del conflicto. Si en 1915 eso había llevado a la firma del Pacto, ahora lo que obtuvo fue la libertad de los dirigentes presos, a cambio de la clausura de la Casa del Obrero y la consecuente disminución de la agitación en ese sector social. ${ }^{2}$

La huelga general habia dejado en claro dos cosas. En primer lugar, evidenció la naturaleza autoritaria represiva del gobierno carrancista, y por tanto minó su legitimidad; pero, más importante todavia, mostró que la experiencia del Pacto no había sido suficiente para acabar con la independencia y la combatividad del movimiento obrero, fincadas en una tradición anarcosindicalista de largos años de lucha.

El propósito de este trabajo es tratar de explicar el triunfo de la línea reformista de acción múltiple durante el régimen de $\mathrm{Ca}$ rranza, considerando que tuvo que imponerse por dos vías.

Por una parte,' como producto de una disputa interna en el movimiento obrero organizado, de la que surge y se desarrolla una corriente reformista que en una coyuntura precisa toma su dirección y al mismo tiempo, como resultado de una política consciente de incorporación de masas de un sector de revolucionarios. Ambos procesos están situados en el marco más amplio de las condiciones de crisis económica posrevolucionaria, y de lucha entre el carrancismo y los sonorenses por el poder nacional.

Por lo demás, la Constitución del 17 estableció los nuevos lineamientos juridicos para la actividad sindical. El artículo 123 definió las relaciones que habria entre las clases sociales fundamentales, bajo la lógica de la conciliación como requisito para el desarrollo capitalista sostenido. Sus propósitos centrales eran los siguientes:

10. fijar los derechos de los obreros en sus relaciones contractuales con el capital, a fin de armonizar, lo más posible, los encontrados intereses de éste y del trabajo, debidos a la "arbitraria distribución de los beneficios obtenidos en la producción"...

2o. a fin de asegurar la estabilidad del desarrollo económico... se proponia definir exactamente la naturaleza del contrato de trabajo, para mantener el equilibrio en las relaciones jurídicas y sociales entre los trabajadores y los capitalistas;

3o. el Estado tenía el derecho incuestionable de intervenir como fuerza reguladora en el funcionamiento del trabajo del hombre cuando fuera objeto de contrato, fijando la duración máxima del trabajo, señalando el salario minimo, etc.;

40. aunque se reconocia la igualdad formal de las partes contratantes, se reconocía la "manifesta inferioridad" de los trabajadores frente a la "omnímoda voluntad" de los capitalistas... se proponía ahora que fuese el Estado revolucionario el que protegiera al obrero mediante las juntas de conciliación y arbitraje y, de esta manera, mediante la conciliación de clases y el arbitraje, resolver los conflictos entre obreros y capitalistas. ${ }^{3}$

La acción del Estado revolucionario y los intentos de organización y reivindicación de demandas por parte de la clase obrera y

- Barry Carr, El movimiento obrero y la politica en México, op. cit., p. 77-78.

José Maria Calderón, op. cit., p. 209. 
los trabajadores en general, no podian obviar estos señalamientos. Necesariamente, su crecimiento y fortalecimiento tendrían que darse en los marcos que la revolución misma construyó.

\section{La politica obrera del Ejecutivo}

Las deterioradas relaciones del presidente Carranza con el movimiento obrero no pudieron mejorar en los tres años de su gobierno. Su actitud frente a los trabajadores siguió caracterizándose por el uso de mecanismos abiertamente represivos, por oponerse a permitir su organización, y en general por la consideración de que o bien no formaban un grupo determinante en las decisiones políticas, o bien que su actuación debía ser limitada.

De cualquier manera, esta postura no impidió la movilización de los trabajadores en defensa de sus niveles de vida. El propio Carranza reconocía, en sus informes de 1917 y 1919 , que durante esos años habían estallado conflictos en Tampico, Tamaulipas, en las zonas mineras de Agujita y Rosita, Coahuila, en Concepción del Oro, Zacatecas, y otros sitios. Solamente de septiembre de 1918 a septiembre de 1919 , señalaba, habian estallado en el país 70 huelgas y 85 paros, resultando desempleados en total 26500 obreros. ${ }^{2}$ Llama la atención que en los conflictos de Cananea y Concepción del Oro, la intervención del Ejecutivo se haya limitado a proporcionar a los cesantes transportes para trasladarlos a otros sitios y, en algunos casos, a colonizar con ellos fincas rurales intervenidas.

Según la peculiar visión del presidente, las huelgas perjudicaban a toda la sociedad, por reducir y encarecer la producción, disminuir el movimiento comercial y colocar en situación crítica a los obreros. Encontró la solución a este problema en conculcar el derecho de huelga establecido en la Constitución. La primera medida en este sentido fue enviar a los gobernadores una circular en la que se les encargaba avisar de aquellas empresas de utilidad pública que hubieran decretado el paro, a fin de que la Secretaría de Hacienda procediera a administrarlas. Según el presidente, esa medida dio tan buenos resultados que la calificó como una mejora racional y progresista en el derecho administrativo.

La circular de referencia -añadia-, sancionando la prevención de la Carta Magna de que los paros son lícitos únicamente cuando el exceso de producción los vuelva indispensables, garantizó el derecho social, sin distinción de clases, al sentar la doctrina de que las fuentes de producción en que se unan la utilidad pública y el lucro privado de los dueños, no pueden cegarse (?) por decisión de propietarios ni de obreros, sin vulnerar el concepto mismo de la riqueza colectiva.

Posteriormente, el Congreso de la Unión, mediante un decreto, corroboró el acuerdo del Ejecutivo. ${ }^{5}$ De esa manera, el Estado mexicano contaría desde entonces con la requisa como arma para desmovilizar y enfrentarse al movimiento obrero. Por otro lado, las distintas facciones revolucionarias representadas en la Cámara

4 Los presidentes de Mexico ante la nación; informes, manifiestos y documentos de 1821 a 1966, Edit. por la XLVI Legislatura, México, Imp. de la Cámara de Diputados, 1966, t. III, p. 204 y 362-363.

Ibid, p. 241. 
de Diputados mostraban su identidad al tratarse de preservar las condiciones de acumulación de capital, por encima del acuerdo o desacuerdo tanto de empresarios como de trabajadores.

Durante los años del mandato constitucional de Carranza, volvió a manifestarse su actitud represiva hacia el movimiento obrero. En marzo de 1918, los trabajadores textiles de Puebla se lanzaron a la huelga en demanda de un aumento salarial del $80 \%$ sobre las tarifas fijadas por Madero en 1912. Su pretensión original habia sido de un $150 \%$, pero ante la actitud intransigente de los patrones, que sólo ofrecian el 55 o $60 \%$, la redujeron a $80 \%$ como propuesta final. Para tratar de acelerar un desenlace a su favor, recurrieron al gobernador del Estado, pero éste se declaró incompetente para actuar a su favor, y finalmente estallaron la huelga el día cinco. De 7000 a 15000 obreros participaron en ella.

- Esta movilización trato de lograr el apoyo de la Cámara de Diputados local, del Ejecutivo municipal y del gobernador. El Congreso se colocó al lado de los huelguistas y decretó un salario mínimo superior al of recimiento patronal, pero los empresarios recurrieron al amparo y tanto el juez de Distrito como la Suprema Corte fallaron en favor de los industriales. Por su parte, Carranza permaneció ajeno al problema. Para cerrar el cerco, las autoridades locales reprimieron con violencia el intento de huelga general del primero de mayo. La derrota fue total para los trabajadores, puesto que algunos regresaron al trabajo con el aumento propuesto por los patrones, a principios de julio, mientras que el resto tuvo que emigrar a otras regiones en busca de nuevo empleo.

$\mathrm{Al}$ año siguiente, también se presentaron casos de represión selectiva. El obrero Diego Aguillón fue secuestrado por los policías de la "reservada" en su centro de trabajo, los Talleres de Indianilla en el Distrito Federal, y conducido a la Jefatura de la Guarnición a eso de las 13:30 horas del 29 de abril. A la sazón ocupaba el cargo de secretario general del Gran Cuerpo Central de Trabajadores de la Región Mexicana (GCCTRM), organización que conservaba la tradición anarcosindicalista en el movimiento obrero, y en tal carácter había asistido a una reunión de ferrocarrileros, haciendo un discurso en que les expresaba su solidaridad, a la vez que los excitaba a la lucha. Sus compañeros creían que ese era el motivo de su detención, y aunque lo ampararon, no apareció?

En el mes de mayo, la capital del pais fue escenario de un nuevo conflicto. La Liga de Maestros, que agrupaba a los profesores de primaria de la ciudad, ante la falta de pagos, y el descenso del poder adquisitivo, convocó y estalló una huelga en el mes de mayo. Este hecho era sintomático de la situación por la que atravesaba el país, además de ilustrar el descontento hacia la política carrancista, ya que se trata de uno de los sectores con mayor capacidad de análisis de los fenómenos sociales. Una de las maestras participantes en el conflicto se sintió obligada a escribirle al presi-

- Pablo González Casanova, "En el primer gobierno constitucional (19171920)", en La clase obrera en la Historia de México, vol. 6, México, Coed. Siglo XXI-IIS/UNAM, 1980, p. 50-61.

${ }^{7}$ Federico Valtierra a VC, 5 de mayo 1919, Archivo de Venustiano Carranza, Centro de Estudios de Historia de México CONDUMEX (en adelante AVC), carpeta 133, legajo 15182, doc. 1 . 
dente para explicar su actitud, "conmovida por la situación aflictiva que atraviesa el profesorado de la capital". En esa carta le decía:

...espero tomará mi participación en este movimiento, no como una rebeldía al gobierno que usted preside: puesto que estudiando la situación actual del pais, este es el momento menos oportuńo para tratar de corregir males económicos y sociales que no han nacido en esta época; sino que vienen de muchos años atrás, y que quizá los medios empleados, no sean los más adecuados para encontrar una solución que responda ampliamente a su posición en la sociedad.

No hace mucho, el maestro de la capital sintió la necesidad de constituirse en una agrupación que le diera fuerza y respetabilidad, y desde luego, me adherí a la idea, porque tengo la convicción de que la armonia social es la base de la fraternidad humana.

Ahora que la Liga de Maestros reclama mi humilde contingente, he estado resuelta a cumplir en nombre de la solidaridad mis compromisos, lamentando profundamente la forma que ha revestido, resultado en mi concepto, de la penuria en que el maestro vive. ${ }^{8}$

La huelga recibió la solidaridad de algunos sindicatos, del GCCTRM y de algunas organizaciones de maestros de provincia. En el estado de Hidalgo se organizaron actividades de ayuda, como funciones de beneficio. El gobernador, Nicolás Flores, para evitar que continuara, ordenó la destitución de los principales activistas. ${ }^{9}$

La posición gubernamental en este contlicto fue precisamente aplicar aquella reglamentación ya mencionada que prohibia la huelga en los servicios públicos, aislando al movimiento y finalmente derrotándolo. El propio presidente declaró en su último informe de gobierno que en ocasión de la huelga:

La ciudad sufrió por varios días algunos transtornos, y el Ejecutivo, que estuvo reprimiendo con prudencia a los trabajadores, publicó su determinación de mantener el orden a toda costa, declarando que no existía el derecho de huelga de los servidores de la Nación e insistiendo en su criterio de que la satisfacción de las apremiantes necesidades colectivas está por encima de la voluntad de cualquier grupo, por respetablę que éste sea. ${ }^{10}$

Un conflicto más, ocurrido a fines del año, en la región textil de Orizaba, fue tan determinante del rumbo que seguiría el movimiento obrero en sus relaciones con el Estado, que merece un tratamiento aparte.

\section{El conflicto textil y el contrato colectivo de trabajo}

La constitución aprobada en 1917 dejaba en libertad a las diversas legislaturas locales para reglamentar lo referente al articulo 123, mediante leyes de trabajo locales. Esto originó disparidades entre los estados, ya que algunos reglamentaron, otros no, e in-

${ }^{8}$ Flenz Espinoza a VC, 13 de mayo 1919, AVC, carpeta 133, legajo 15236, doc. 1.

9 Rosendo Salazar, op. cit., t. I, p. 249-250. Desplegado del Comité de Profesores y Obreros Pro Auxilio de Maestros del Distrito Federal, Pachuca, Hidalgo, mayo de 1919, AVC, carpeta 113, legajo 15266, doc. 1; Nicolás Flores a VC, 4 de junio de 1919, AVC, carpeta 135, legajo 15370, doc. 1.

${ }_{10}$ Los presidentes de México ante la nación, op. cit.. t. III, p. 307. 
clúso entre los primeros se interpretó de diversas maneras el texto constitucional. En Veracruz, en el mes de enero de 1918, se promulgó la Ley del Trabajo que, en lo esencial, respetaba el espiritu del artículo 123, estableciendo entre otras cosas el contrato colectivo de trabajo y el reparto de utilidades como derechos de los trabajadores. Esto provocó desde entonces el rechazo de los industriales de la región, quienes solicitaron al presidente su intervención para que la ley de marras fuera aplazada, en tanto no se expidiera una ley federal del trabajo."

El gobernador, Cándido Aguilar, defendió la ley local, señalando que venía a llenar una necesidad imperiosa de la revolución.

Lo reclamaban -decia-, sobre todo, la pugna incesante que el resurgimiento del proletario a la vida de la libertad por una parte y la humana defensa que el capitalista hacia de sus antiguas prerrogativas, habia creado en este medio en que el trabajo impera.

En vista de ello, continuaba, se habia buscado la solución más equilibrada. Pero ello no quería decir que fuera definitiva, sobre todo en lo tocante al reparto de utilidades, siempre y cuando los capitalistas propusieran soluciones prácticas.

En ese contexto, a fines de 1919, el 22 de octubre, estallaron una serie de huelgas en el estado, con la participación de alrededor de 12 mil obreros. El origen de las mismas estuvo en la iniciativa patronal de abrir un segundo turno en la fábrica de Cocolapam, mediante la contratación individual. El sindicato de la fábrica se negó a aceptar tal procedimiento, exigiendo la.contratación preferente para los obreros sindicalizados. Ante el rechazo a esa propuesta, la huelga estalló, y se extendió rápidamente a otros centros obreros. En este conflicto se jugaban al menos dos cosas: una conquista fundamental como la contratación colectiva y, dado que el conflicto se producía en plena campaña presidencial, la definición de las alianzas que podía establecer el movimiento obrero, o bien la alternativa de mantener su independencia ante el enfrentamiento entre los obregonistas y la candidatura oficial patrocinada por Carranza.

El gobierno central, a través de su prensa, propagó la versión de que se trataba de un movimiento con fines políticos, esto es, para apoyar a Obregón. El secretario general de la Federación de Sindicatos Obreros del D. F., Samuel O. Yúdico, desmintió categóricamente esa versión, señalando que la huelga obedecía a cuestiones económicas perfectamente conocidas. ${ }^{13}$

El primero de noviembre de 1919 se dieron a conocer las condiciones que ambas partes ponian para solucionar el conflicto. Los obreros, en un documento fechado el 26 de octubre, proponian la reanudación de labores mientras se llegaba a una resolución definitiva, exceptuando al segundo turno de la fábrica de Cocolapam. Para resolver el conflicto, pedían la intervención de la Sala Primera de la Suprema Corte de Justicia del Estado, quien determinaría si la cláusula segunda del conveniọ de trabajo, firmado el 19

\footnotetext{
"Angel Lagarda a VC, 27 de diciembre 1918, AVC, carpeta 128, legajo 14606, doc. 1 .

12 Declaraciones de Aguilar, 8 de enero 1919, AVC, carpeta 129, legajo 14725, doc. 1 .

${ }^{13}$ El Monitor Republicano, 1 de noviembre 1919.
} 
de enero de 1916, en que se estableció la contratación a través del sindicato, contravenía de alguna manera a la legislación en vigor. En cualquier caso, agregaban, debía firmarse un nuevo contrato colectivo, con la asistencia de un tercero, que podria ser el gobernador, en el que, dependiendo de la resolución judicial, debia incluirse la misma cláusula en discusión. La parte patronal, el 28 de octubre, hizo una contrapropuesta. Según ella, las fábricas debían abrir sus puertas con personal cubierto a elección de los administradores con contratos individuales, incluyendo un máximo del $80 \%$ de los que laboraban al declararse la huelga. Era obvio que todos los turnos estaban incluidos en esta proposición. Por lo demás. dejaban el debate de la conflictiva cláusula para la Junta Central de Conciliación y Arbitraje, aclarando que podían utilizarse todos los recursos legales existentes en el proceso, inclusive el amparo. En caso de que el laudo favoreciera a los patrones, se darian por terminados los contratos sin responsabilidad del patrón, y en el caso contrario, continuaría el contrato "con las modificaciones que el mismo laudo decrete, o bien el patrón dará por terminado el contrato indemnizando a los obreros que no quieran aceptar, con tres meses de salario". 14

Como puede apreciarse, los empresarios trataban de poner sobre el tapete de las discusiones la cláusula de la contratación colectiva, claramente favorable a los trabajadores, mientras que éstos centraban su defensa en el hecho, por demás patente, de que esa cláusula no contradecía en absoluto al artículo 123.

Lo cierto es que la Confederación Regional Obrera Mexicana (CROM) capitalizó el conflicto para convertirlo en un problema que involucró a las principales fuerzas políticas del momento. El primer dia de noviembre envió un boletin a sus federaciones afiliadas, en el que apuntaba la realización de gestiones ante la American Federation of Labor (AFL) de Samuel Gompers, para solicitar su comprensión y solidaridad. Pero, lo que es más importante, alertaba a las organizaciones sobre la posibilidad de hacer estallar la huelga general de solidaridad, de acuerdo con el artículo 30 del Pacto de Solidaridad firmado en Zacatecas. El comunicado lo firmaban el secretario general, Antonio Valdés, y el del Exterior, José G. Escobedo. ${ }^{15}$ Dos días después reiteraban su posición y fijaban la importancia del conflicto con la siguiente conclusión:

Que el Capitalismo Organizado en la Región Veracruzana, ha demostrado una actitud intransigente, a cuantas proposiciones se le han hecho hasta ahora, las que han consistido en poner punto final al estado de cosas reinante en los actuales momentos en aquellos lugares fabriles, lo que indica claramente que en esta vez la coalición capitalista pretende dar un golpe de muerte a la Organización Obrera, que constituye la Cámara del Trabajo, con el deliberado objeto de poner a salvo de nuevos transtornos sociales sus propios intereses, dando así un golpe moral de gran peso y de suma importancia al Movimiento Obrero de la República. ${ }^{16}$

Con la finalidad de lograr mayor repercusión del conflicto, la Federación de Sindicatos Obreros del D. F., perteneciente a

is Ibid., 1 de noviembre 1919.

15. Ihid., 2 de noviembre 1919.

it lhid., 4 de noviembre 1919. 
la CROM, dirigió a la Cámara de Diputados una comunicación en la que solicitaba, por ser de interés nacional el problema, la intervención del Ejecutivo, para buscar los medios de rápida solución. Aunque a propuesta del presidente de la Cámara en turno, Agustín Franco, sólo se transcribió el comunicado al Ejecutivo, esta salida encontró la oposición de los diputados del Partido Liberal Constitucionalista (PLC), el cual, por diferencias políticas, se habia desligado del Presidente y apoyaba decididamente a Obregón. Dos de ellos, Altamirano y Espinoza, hicieron intervenciones enérgicas. El primero se encargó de poner de relieve la actitud parcial del gobierno. Dijo:

...desgraciadamente, señores, por la apatía del gobierno, por la apatía de las autoridades, que todavia ven como una cosa que no debe tomarse en consideración a la fuerza obrera, no ha podido llegarse a ningún resultado. Al contrario, se ha provocado la ira de los obreros, de las clases trabajadoras, mandando artillar la Catedral de Córdoba, impidiendo que unas comisiones nombradas por los obreros llegaran hasta Córdoba a hablar con el gobernador interino, don Armando Deschamps, y se ha hecho uso de toda clase de medios apremiantes para obligar a los obreros a desistir de su actitud.

Por eso, proponia designar una comisión que hablara con el Presidente y llamara a las partes a solucionar el conflicto, para evitar matanzas y desórdenes. Puede apreciarse que ellos, los obregonistas, sí consideraban importante aliarse a los obreros, o mejor dicho, ligarlos a su causa.

El otro diputado, Espinoza, lanzó graves acusaciones contra el presidente Carranza.

Porque ya sabemos bien, ciudadanos representantes - dijo-, que el ciudadano Presidente de la República por sí solo, al recibir este papel, el oficio que nosotros le enviemos, no haría más que enviarlo al cesto, como hace con todo lo que va de esta Representación Nacional. El Ejecutivo que para sostenerse ha claudicado, aliándose de una manera descarada con el capital y el clero, ¿va de su propia y espontánea voluntad a ponerse en este conflicto del lado de los obreros? Es absurdo concebir esta idea, ciudadanos representantes. El ciudadano Presidente de la República como todo dictador, estará con toda la fuerza de poder que tiene en las manos, del lado del capital para ahogar una vez más las aspiraciones justas del mejoramiento del proletariado mexicano. ${ }^{17}$

En el conflicto se reflejaban también los problemas que enfrentaba el Presidente con una Cámara de Diputados dividida y cada vez más inclinada al bando obregonista.

En vista del alargamiento del conflicto, finalmente el Ejecutivo Federal tomó la decisión de intervenir. El 11 de noviembre Carranza declaró que "el Gobierno estaba dispuesto a intervenir para buscar la forma más conveniente de armonizar los intereses de ambas partes y que al efecto iba a dar desde luego instrucciones al señor general Plutarco Elías Calles, para que estudiara las bases para su arreglo". "Calles había sido llamado pocos días an-

${ }^{17}$ Diario de los Debates, año II, Periodo Ordinario XVIII Legislatura, t. III, núm. 43, 4 noviembre 1919, p. 5-10; El Monitor Republicano, 12 de noviembre 1919.

18 El Monitor Republicano, 12 de noviembre 1919. 
tes de Sonora, donde era el gobernador constitucional, para ocupar la Secretaria de Industria, Comercio y Trabajo en el gabinete carrancista, aunque el objetivo no fue precisamente promoverlo, sino alejarlo de sus bases de apoyo y tenerlo bajo control en la coyuntura de la campaña presidencial, dada su filiación claramente obregonista.

La CROM siguió promoviendo acciones de propaganda y preparación de sus organizaciones afiliadas para auxiliar a los obreros en huelga. Entre las medidas que tomó destaca el boicot a los productos procedentes de las fábricas de Orizaba. ${ }^{19}$

La intervención de Calles en el problema dio un giro a la situación. El 20 de noviembre del mismo año de 1919 se hicieron públicas sus proposiciones para solucionarlo. Estas eran:

Primera: Entrañando el actual conflicto entre el capital y el trabajo; una cuestión principalmente legal, según declaraciones de los interesados, éstos deberán discutir sus derechos ante las autoridades respectivas, para que ellas resuelvan lo que en justicia corresponda.

Segunda: Como la paralización de las industrias causa transtornos de diversos órdenes, no sólo a los dos contendientes, sino también a la sociedad en general y entre ésta al Poder Público; entre tanto se discuten por los medios legales y se fijan por las autoridades respectivas los derechos de cada uno, los obreros e industriales de Orizaba, deberán de poner, desde luego, las cosas en el mismo estado en que estaban el dia veinte del pasado octubre, es decir, las fábricas trabajarán en las mismas condiciones y con el personal que antes tenian.

Y en caso de no aceptarse dichas condiciones, dejaba entrever la posibilidad de la incautación de las empresas por el Estado. ${ }^{20}$

Por su parte, los industriales también hacian labor entre los dirigentes estatales. En un memorándum dirigido al secretario de Gobernación, Manuel Aguirre Berlanga, defendian su postura como una extensión de los principios contenidos en la Constitución, pues:

Conceder la preferencia que piden los [...] obreros, seria prescindir, por parte de los industriales, del innegable e ilimitado derecho de contratación, y al mismo tiempo vendría a imponerse a los obreros una obligación de asociarse, que las leyes constitucionales no consignan como obligación; sino como derecho....

A pesar de la presión de Calles para apresurar la solución, los industriales no cedieron. Ello obligó al secretario a enviar una nota a los periódicos, en la que acusaba a los empresarios de haber cerrado las puertas a un arreglo conciliatorio, ya que no habian aceptado su propuesta inicial, ni una posterior de aceptar el contrato colectivo con algunas restricciones "que evitaran en lo futuro las irregularidades de que se quejan, y garantizándoles su cumplimiento por parte de los obreros". Igualmente, reafirmaba la postura del gobierno de "llegar hasta la incautación de las fábricas, o a prestar su ayuda a los huelguistas a aquellas de sus pretensiones que aparecen justas".

14 Ibid., 18 de noviembre 1919.

20) Ihid., 20 de noviembre 1919.

2 J. Nava a Manuel Aguirre Berlanga, 21 de noviembre 1919; AVC, carpeta 142, legajo 16496, doc. 1 . 
En la misma nota, para que no quedara duda sobre su posición, afirmaba:

Aunque los industriales niegan que tratan de destruir a los sindicatos, se ve claramente que todos sus pasos se encaminan a este fin y que de ello han hecho punto de amor propio. ${ }^{22}$

En este contexto, en el que las negociaciones continuaron por varios dias sin resultados positivos, en gran medida por las tácticas dilatorias de los industriales, el general Calles hizo declaraciones que ilustran muy bien sus diferencias con Carranza. En una entrevista de prensa del día 24 de noviembre, afirmó que de aceptarse el contrato individual, se violarian las leyes y se retrocedería medio siglo,

siendo así que para proteger a la Nación del movimiento en embrión bolsheviqui, que amenaza a todos los paísés del planeta, es el momento de hacer concesiones al proletariado, no de exasperarlo y pretender en vano destruirlo como entidad social. ${ }^{23}$

Los industriales hicieron un último intento por acercar al Presidente a su causa. En un largo memorándum firmado por la CONCAMIN y los industriales locales, le explicaban detalladamente el problema e insistían en su tesis de que la contratación libre era un derecho garantizado por la Carta Magna, por lo que la exigencia obrera violaba garantías individuales: inclusive la de asociación de los propios trabajadores. ${ }^{24}$

Finalmente, gracias a la resistencia obrera, a su movilización, al apoyo generado en el plano nacional, sobre todo a través de la CROM, $\mathrm{y}$ por supuesto a la presión de Calles tanto frente a $\mathrm{Ca}$ rranza como frente a los industriales, el 29 de noviembre de 1919 se firmó, ante el presidente, un convenio con las siguientes bases:

Primera. Los obreros e industriales de Orizaba reanudarán los trabajos en las fábricas del Cantón, en las mismas condiciones en que estaban trabajando el veintiuno de octubre del presente año.

Segunda. A todos los obreros que estuvieren ausentes o que por cualquier otra causa no pudieren concurrir al trabajo, los industriales les concederán un plazo de un mes, contado desde la fecha de esta acta, para que puedan volver a ocupar los puestos que tenían el ventiuno de octubre. Pasado este plazo, los industriales podrán reemplazar a los obreros que no se hubieran presentado.

Tercera. El presente conflicto será resuelto por la Junta Central de Conciliación y Arbitraje, la cual quedará integrada con el personal que tenía al estallar la huelga.

Cuarta. El trabajo continuará en todas las negociaciones en la misma forma en que se reanuda, hasta que por los trámites legales queden solucionadas las dificultades que originó esta huelga. ${ }^{25}$

EI Monitor Republicano, 21 de noviembre 1919.

23 Ibid., 25 de noviembre 1919.

24 CONCAMIN a VC, 27 de noviembre 1919, AVC, carpeta 142, legajo 16496, doc. 4.

${ }_{25}$ Acta de aceptación de obreros e industriales a bases de $\mathrm{VC}$ para resolver el conflicto de Orizaba, 29 de noviembre 1919, AVC, carpeta 142, legajo 16511 , doc. 2. 
Los obreros habian obtenido el triunfo y la conservación de una conquista sindical importante, pero para lograrlo habían tenido que recurrir a la fuerza de una de las dos corrientes que en ese momento se disputaban el poder político. La alianza con Obregón y Calles revelaba su debilidad como clase social constituida para sí, a la vez que abria un nuevo camino para alcanzar algunas conquistas. Ya no el de la negativa a participar en la lucha política, sino el de la alianza y negociación de cúpula con algunas fuerzas de dentro del poder público. Eso, era claro, implicaba la pérdida de la autonomia y conducia a la desmovilización de la base obrera. Por otro lado, para los sonorenses fue una excelente oportunidad de estrechar relaciones con el movimiento obrero y subordinarlo a su estrategia, para finalmente convertirlo en su base de apoyo.

\section{El Congreso de Saltillo. La Confederación Regional Obrera Mexicana (CROM)}

Los intentos de organización nacional de los trabajadores mexicanos, después de la huelga general de 1916 y la desarticulación de la Casa del Obrero Mundial, culminaron en 1918, con la creación de la CROM. Pero antes se había tratado de lograrlo en dos ocasiones, que vale la pena consignar.

En enero de 1916 fue fundada la Federación de Sindicatos Obreros del D. F. (FSODF) por los miembros de un grupo que habia pertenecido a la Casa del Obrero Mundial y que se reunía para estudiar y discutir los problemas del movimiento obrero y tratar de llevarlo a la acción. Encabezaba este grupo, llamado desde 1918 Grupo Acción, el trabajador electricista Luis N. Morones, quien se habia destacado como lider de su gremio desde 1915, cuando el descenso del poder adquisitivo del salario condujo a los trabajadores de la capital a realizar una serie de huelgas y movilizaciones. En enero de 1915 el Sindicato Mexicano de Electricistas presentó pliegos petitorios a la Compañía Telefónica y Telegráfica Mexicana, a la Compañia de Luz y Fuerza del Centro, y a la Compañía de Teléfonos Ericssonn, en demanda del reconocimiento del sindicato y de aumento general de salarios. Ante la negativa de las empresas para aceptar estas demandas, el general Obregón, que entró a la ciudad el 4 de febreró, incautó la empresa y la puso en manos de los trabajadores, quienes eligieron en asamblea a Morones para ocupar el cargo de gerente, con un salario muy superior al de los trabajadores, $\$ 600.00$ mensuales, y sujeto a responder ante el sindicato de sus actividades. ${ }^{26}$

Entre los dirigentes aprehendidos. en la huelga general de 1916 estuvo Morones, quien al salir de la cárcel se encontró desempleado. Para fortuna suya, un amigo había sido electo presidente municipal de Pachuca, y lo llamó a ocupar el cargo de secretario del Ayuntamiento. Ahí aprovechó su estancia para organizar a los trabajadores del sector eléctrico e incorporarlos al Sindicato Mexicano de Electricistas. ${ }^{27}$

\footnotetext{
26 Víctor Manuel Sánchez Pérez, Surgimiento del sindicalismo electricista (19141917), México, FCP y S/Unam, 1978, p. 168-186.

27 Pablo González Casanova, "En el primer gobierno constitucional (1917. 1920), op. cit., p. 71.
} 
En realidad, todos los miembros del grupo tenian actividad entre algunos gremios obreros, lo que explica que para la fundación de la FSODF, en enero de 1916 , se reunieran catorce sociedades y sindicatos, entre los que había peluqueros, carpinteros, albañiles, electricistas, empleados, obreros de artes gráficas, etc. Esta Federación, más que un cambio en el terreno ideológico, en que predominaba la acción directa como concepción de lucha, de tradición anarcosindicalista, contribuyó al desarrollo del movimiento obrero con una nueva forma de estructura organizativa, más formal, que era la confederal, según la cual cada sindicato tenía representación en el Consejo Federal, órgano máximo de dirección y representación, y cada sindicato, a la vez, era autónomo en lo tocante a sus cuestiones internas. ${ }^{28}$

La FSODF convocó a un Congreso Preliminar Obrero, que se celebró en Veracruz del 6 al 17 de marzo de 1916. Allí se reiteraron como principio fundamental de la organización obrera la lucha de clases, y como su finalidad suprema la socialización de los medios de producción. Para lograrlo, se emplearia "exclusivamente la acción directa, quedando excluida del esfuerzo sindicalista toda clase de acción política, entendiéndose por ésta el hecho de adherirse oficialmente a un gobierno o a un partido o personalidad que aspire al poder gubernativo". Además, como consecuencia de ello, dejaría de pertenecer a la nueva organización, denominada Confederación del Trabajo de la Región Mexicana, todo aquel que ocupara un puesto público. Finalmente, en cuanto a la estructura, se adoptaba la organización confederal. ${ }^{29}$ En todo caso, esta Confederación tuvo una existencia efímera.

Aun cuando la línea de la acción directa se había conservado, contó con la oposición de los delegados del D. F., lo que fue patente hacia el exterior más tarde, cuando el 20 de febrero de 1917 , Morones y su grupo publicaron un manifiesto en el que hacian pública la creación del Partido Socialista Obrero, así como su determinación de lanzar candidatos a diputados federales. Argumentando el desastre del año anterior, planteaban la necesidad de abandonar la acción directa y pasar a la acción múltiple, "no sólo para evitar en lo porvenir desastres como los del año pasado, sino también para impedir que nuestros sindicatos mueran y que la clase obrera vuelva, después de los cruentos sacrificios realizados, a su antiguo estado de embrutecimiento y servilismo".

Después, explicitaban los objetivos de esa ampliación de los métodos de lucha.

No esperamos que nuestros diputados consigan para los obreros grandes mejoras, ni mucho menos que lleven a cabo todas nuestras aspiraciones; pero sí pueden ser una ayuda eficaz para nuestros movimientos emancipadores. El objeto principal es que los sindicatos tengan, en caso necesario, donde escudarse, y que si por desgracia vuelve a llegar el momento en que las bocas de los famélicos estén amordazadas, haya compañeros en posibilidad de hacer oir la voz de los parias oprimidos. ${ }^{30}$

Fuera de esas consideraciones de orden práctico, el nuevo par-

is Rocio Guadarrama, Los sindicatos y la política en México: la CROM (19181928). México, Ed. Era. 1981, p. 30-33.

${ }_{29}$ Rosendo Salazar, op. cit., t. I, p. 146-147.

${ }^{30}$ Ibid. , p. 196. 
tido no reivindicaba un programa definido. Por lo demás, sin apoyos fuertes, su participación en la justa electoral resultó un fracaso. No obtuvieron un solo escaño, pero el nuevo rumbo tomaba mayor fuerza.

En octubre de 1917, se realizó un nuevo intento de unificación: el Segundo Congreso Nacional Obrero, en Tampico, convocado por la Casa del Obrero local. A este nuevo congreso asistió una numerosa delegación del D. F., dominada por los sindicalistas partidarios de la acción múltiple. Morones, en este caso, representaba a los electricistas de Pachuca. El enfrentamiento de esta corriente con las organizaciones anarcosindicalistas fue lo más importante del Congreso. El crecimiento de la primera se aprecia en el hecho de que en esta ocasión no pudieron imponerse en las conclusiones las tesis aprobadas en Veracruz.

De las resoluciones nos interesa señalar que se recomendó la organización gremial, sindicalista; se declaró que las agrupaciones obreras tenían como fin resolver el problema económico y social del trabajador, y que, por tanto, "la propaganda doctrinaria deberá ser hecha conforme a la capacidad moral de :los elementos asociados como labor educativa que marque orientación hacia el fin que se persigue"; y se juzgó indispensable "la formación de grupos fuera de los organismos obreros, que se encarguen de estudiar y propagar todo lo que dentro de la órbita ideológica se crea pertinente hacer del conocimiento del trabajador". A fin de coordinar las acciones de los asociados, se designó a un Comité Central con sede en Torreón. ${ }^{31}$ La acción directa estaba llegando a su término pero los intentos de la corriente de acción múltiple no pasaron de allí.

Estando así las cosas, el 9 de marzo, el gobernador de Coahuila, Gustavo Espinoza Mireles, prominente miembro del Partido $\mathrm{Na}$ cional Cooperatista (PNC) y antiguo secretario particular de Carranza, hizo pública una invitación a las organizaciones obreras para la celebración de un Congreso Obrero en Saltillo. Hasta el momento no ha sido posible precisar si la iniciativa de convocar al evento partió exclusivamente del gobernador, bajo la influencia de un colaborador cercano, líder obrero, Juan Lozano, o habia obedecido a indicaciones del Presidente. La segunda hipótesis resulta tanto más difícil de sostener, dadas las malas relaciones del PNC con el Partido Liberal Nacionalista, que contaba con la protección oficial. Sea lo que fuere, tal vez para Carranza representaba una buena posibilidad de atraerse al movimiento obrero.

En la convocatoria del evento, se tuvo especial cuidado en recalcar que la discusión sería libre, y que las decisiones serían tomadas por los obreros mismos, sin presión alguna. Algunos dirigentes como Jacinto Huitrón y Morones se encargaron de difundir esa versión y de invitar a-asistir al Congreso, que debía inaugurarse el 1 de mayo. Las organizaciones de mayor tradición se encontraron ante la disyuntiva de marginarse del proceso o bien de dar la lucha al interior del mismo. Aparentemente la segunda opinión triunfó, yà que se reunieron en Saltillo 115 delegados, representantes de unos siete mil trabajadores. ${ }^{32}$

31 Ibid., p. 204-205.

32 Rocío Guadarrama, op. cit., p. 42. 
Aunque el Congreso contó con la participación de todas las corrientes representativas del movimiento obrero de la época, la correlación de fuerzas se reflejó en la composición del Comité Ejecutivo de las sesiones: Jacinto Huitrón, anarcosindicalista, secretario general; Morones, reformista, secretario del Interior, y Ricardo Treviño, también representante del nuevo sindicalismo, secretario. El nombre que adoptó la nueva organización fue el de Confederación Regional Obrera Mexicana (CROM).

En cuanto a los principios fundamentales, se sostenía el radicalismo anterior, al señalar la lucha de clases como un derecho moral de los trabajadores. En el terreno organizativo, se aprobaron nuevamente las tesis de Tampico, según las cuales se respetaba la autonomia organizativa interna, se adoptaba el federalismo para las cuestiones generales, se definia a los sindicatos como cuerpos hechos para resolver el problema económico y social de los trabajadores, y se recomendaba la creación de agrupaciones doctrinarias externas a los sindicatos.

El programa de demandas aprobado mostraba realmente los cambios introducidos en el Congreso. Se trataba de un programa completamente reformista, cuyo objetivo, según Morones, era permitir el paso a la acción. En lo tocante a la agricultura, los delegados se pronunciaron por el reparto de tierras, y el fraccionamiento de las tierras cultivables, ofreciendo su concurso para ello.

Respecto a la industria, demandaban:

a) Que se preste toda clase de apoyo a las agrupaciones obreras para la crèación de la pequeña industria ya sea poniéndola directamente en manos de los obreros, ya decretando la exención de los derechos aduanales sobre todos los útiles destinados a las aplicaciones inherentes a la agricultura y a la industria destinados a los productores en pequeño.

b) Que se dé posesión inmediata a los obreros, de los fundos mineros que han caducado y caduquen para trabajarlos por su propia cuenta, incluyendo a aquellos que por la maldad de los concesionarios estén sin explotarse.

En el renglón de la previsión social, demandaban la reglamentación del artículo 123 contando con la opinión de los obreros; que los acuerdos de las Juntas de Conciliación y Arbitraje fueran ejecutados tres días después de dictado el fallo, sin que procediera el amparo; y que los contratos de trabajo se elaboraran por mediación de las agrupaciones sindicales. ${ }^{33}$

Por lo que se refiere a la organización de la CROM, un rasgo sobresaliente es el peso que se le otorgó al secretario general dentro del Comité Central, y la centralización de las decisiones en el propio Comité Central. Por lo demás, el Grupo Acción, gracias a su disciplina y unidad, logró imponer desde entonces el rumbo a la nueva central. La acción múltiple por fin se habia entronizado en el movimiento obrero. La elección de secretario general solamente confirmó esa tendencia. Por 85 votos contra 6, Morones fue électo para ese cargo. Además Ricardo Treviño resultó secretario del Interior, y J. Marcos Tristán del Exterior.

Una de las medidas iniciales que tomaron estos dirigentes fue

3 Barry Carr, op. cit., p. 91-92. Pablo González Casanova, op. cit., p. 74-80; CC de la CROM a VC, 7 mayo 1919, AVC carpeta 133, legajo 15197, doc. I y legajo 15159, doc. 1 . 
escribirle al presidente Carranza e informarle de las resoluciones, ofreciéndole su apoyo para lograr llevarlas a la práctica, así como de las vinculaciones con la American Federation of Labor, de Samuel Gompers. ${ }^{34}$

\section{La AFL y el movimiento obrero mexicano}

El interés de la AFL y su dirigente, Samuel Gompers, por México, no era nuevo para la época de la creación de la CROM; se remontaba al menos a los últimos años de la dictadura porfirista. En general puede decirse que su actividad se orientaba por tres cuestiones básicas:

a) Era parte de la disputa interna por el control obrero, frente a la Internacional Workers of the World (IWW), organización anarquista que tenía fuerte presencia en el sur de Estados Unidos, con vinculos fuertes con el magonismo, y sucursales entre trabajadores mexicanos en Tampico, Guadalajara, Sonora, Morelia, y la ciudad de México. Además, se daba en el contexto de la situación de preguerra, con la persecusión de la izquierda norteamericana y la expulsión de activistas extranjeros del país. Así, en la medida en que la AFL pudiera vincularse a las organizaciones obreras mexicanas, las alejaria de la influencia tanto de la Iww como de otras organizaciones, entre ellas la II Internacional. ${ }^{35}$

b) La AFL trataba en ese momento de ganar mayor espacio politico en la administración de Wilson, y ello podía lograrse realizando tareas diplomáticas de apoyo a su política exterior. Por supuesto. Gompers pensaba que para ello podia utilizar al movimiento obrero para, por ejemplo, obligar a Carranza a abandonar la política de neutralidad en la guerra, y sumarse al campo aliado. De hecho, con el ingreso de Estados Unidos a la guerra se dio también el fin de lo que Gompers llamaba la lucha "económica" en el terreno sindical, ya que se le incorporó a la Comisión Consultiva del Consejo de Defensa Nacional, organismo creado para generar una economia de guerra. A partir de ello, la AFL organiza la Alianza Americana para el Trabajo y la Democracia, que hace propaganda proguerra y recibe cuantiosos subsidios estatales. En pago, por supuesto, los obreros norteamericanos no realizarian ningún movimiento huelguístico.

c) Con la lógica de los dos procesos descritos, la AFL buscaba constituir una Federación Panamericana del Trabajo, que sirviera de contención al comunismo y/o anarquismo en América Latina, a la vez que constituyera la vía de introducción de una política sindical reformista o al menos no hostil a los Estados Unidos.

Guiada por ese marco ya a mediados del 1916, la AFL hizo una invitación a la Casa del Obrero Mundial para tener una reunión conjunta. Demagógicamente planteaba como necesario que los trabajadores de ambos países declararan que no pelearían entre ellos, para evitar una guerra.

Tanto la COM como la FSODF aceptan la invitación y envían de

${ }^{3+}$ CC de la CROM a VC, doc. cit.

${ }^{35}$ Para la redacción de este acápite se ha utilizado fundamentalmente, salvo indicación expresa, el texto de Harry A. Levenstein, "Labor organizations in the United States and Mexico. A history of their relations", Contributions in American History, núm. 13, Greenwood Publishing Company, 1971, capitulos 1 al 6, p. 13-93. 
inmediato una nutrida delegación a Eagle Pass, Texas. Sin embargo, no encuentran ahí a los delegados de la AFL. Después de un intercambio de notas, aceptan que dos delegados viajen a Washington, aunque con facultades limitadas. Salvador González y Luis Morones son los designados, y llegan a Washington el 1 de julio de 1916.

Esta aceptación tiene mucho que ver con el alineamiento que hasta entonces tenía la COM con el gobierno de Carranza, al que deseaban ayudar evitando la intervención norteamericana. Sus lideres pensaban que con el apoyo de la AFL podría lograrse.

En esa reunión también participaron Carlos Loveira y Baltazar Pagés, enviados de Salvador Alvarado con el objeto de trabajar por la Federación Panamericana del Trabajo, así como por el apoyo a la revolución mexicana. En esa oportunidad:

Una "declaración conjunta" fue firmada llamando a convocar otra conferencia, en la cual los trabajadores de ambos países, completamente representados, formularan planes para mantener relaciones permanentes entre los movimientos obreros de los dos países, así como para el establecimiento de una Federación Pan-Americana del Trabajo. $^{36}$

Si bien esto no representó un gran avance, incluso porque poco después ocurre la represión a la huelga general del D. F. y la consecuente desaparición de la COM, no debiera desestimarse la influencia de este viaje para reafirmar la línea reformista de Morones.

Poco después de creada la CROM, la AFL envía una comisión a México, compuesta por John Murray, Santiago Iglesias y James Lord, con el objeto de avanzar en su estrategia proguerra. Sin embargo, se tropiezan con la oposición de algunos dirigentes, entre ellos Morones, que denuncia la labor del Consejo de Defensa Nacional. Ello obliga a Iglesias a negar su proyecto y a declarar que:

... con el creciente movimiento de capital de los Estados Unidos a México, seria necesario para el movimiento obrero mexicano poder contar con el apoyo de sus camaradas en los Estados Unidos en su lucha por defender sus derechos. ${ }^{37}$

Es claro que Iglesias reconocía el peso del anarquismo en México y a la vez la mala imagen de la AFL, y trataba en consecuencia de mostrarse lo más avanzado posible. La respuesta final de la CROM fue bastante vaga; aceptaban trabajar juntos en la protección de trabajadores inmigrantes, pero no aceptaban todavía establecer relaciones formales.

Sin embargo, faltaba poco para la consumación de la alianza. En julio de 1919 se fundaba la PAFL en Nueva York, con la destacada participación de la CROM. Además es digno de notarse que a pesar del progresivo distanciamiento entre la CROM y Carranza, los sucesivos viajes de Morones al vecino país fueron subsidiados por el Ejecutivo; como puede verse en la siguiente comunicación del Presidente al subsecretario de Relaciones Exteriores, Hilario Medina:

${ }^{36}$ Harry Levenstein, op. cit., p. 45.

${ }^{37}$ Ibidem, p. 69. 
Hoy digo al C. Melquiades García, Cónsul de México en Laredo, Texas, lo siguiente:

Entregue usted al Sr. Luis N. Morones la cantidad de mil ochocientos dollars con cargo a la Secretaría de Relaciones Exteriores. Lo transcribo a usted a fin de que ordene se cargue esa cantidad a la partida de gastos secretos de esa secretaría. ${ }^{38}$

Por distintas vias y circunstancias, las organizaciones hegemónicas obreras de México y Estados Unidos llegaban a una estrategia reformista común, pero que claramente servía más a los proyectos de la AFL. En todo caso, no podemos descartar su influencia-como modelo organizativo e ideológico- en la CROM y en su dirigente, Luis Morones.

\section{La alianza entre la CROM y los sonorenses}

A pesar de que el crecimiento de la CROM fue lento hasta 1920 , su preeminencia en el movimiento obrero era indiscutible, entre otras cosas por la falta de una agrupación que ofreciera una alternativa de organización revolucionaria. Algunos sindicatos salieron de la CROM y crearon el Gran Cuerpo Central de Trabajadores, pero su actividad fue marginal. El recién formado Partido Comunista Mexicano fue constituido por un grupo de militantes extranjeros y por algunos activistas nacionales, y su actividad no fue muy importante. Por lo demás, algunos de ellos, como Manabendra Nath Roy y el aventurero norteamericano Gale, mantenían o buscaban mantener buenas relaciones con el presidente Carranza. Incluso el primer secretario general del partido, José Allen, era un agente de inteligencia militar norteamericano.

La nueva táctica adoptada pronto rindió frutos: Ante el inicio de la campaña presidencial y la clara separación de Obregón y Carranza, los líderes de la CROM decidieron tomar partido por el primero de ellos, con quien habian tenido contacto desde tiempo atrás. Para darle formalidad a la alianza que establecían se firmó un pacto, mantenido en secreto hasta 1930, con fecha 9 de agosto de 1919. A cambio del apoyo obrero a su candidatura, Obregón se comprometía, en caso de resultar electo, a que:

1) Se crearia una Secretaría del Trabajo a cargo de la cual estaría una persona estrechamente identificada con los intereses obreros.

2) Hasta la creación de esta secretaría especial, la Secretaria de Industria, Comercio y Trabajo existente, estaria a cargo de una persona estrechamente identificada con los obreros.

3) La Secretaría de Agricultura se confiaria a una persona bien preparada para el cargo, la cual tendría en cuenta las recomendaciones del grupo obrero en materia de agricultura.

4) En la designación de las personas mencionadas en las cláusulas 1 , 2 y 3 deberían tenerse en cuenta las recomendaciones del Partido Laborista que se iba a crear.

6) Se concedería personalidad legal al comité central de la Confederación Regional Obrera Mexicana de modo que pudiera tratar directa-

${ }^{38}$ VC a Hilario Medina, 25 octubre 1919, AVC, carpeta 141, legajo 16361, doc. 1 .

${ }^{39}$ Pablo González Casanova, op. cit., p. 139-170. Barry Carr, op. cit., p. 98-108. 
mente con el secretario de Industria, Comercio y Trabajo y con el presidente.

7) El comité central tendría oportunidad de consultar con el presidente acerca de los temas laborales por lo menos un día a la semana.

10) A la Confederación Regional Obrera Mexicana y al Partido Laborista se le concederían todos los medios para la propaganda y la organización obrera en todo el país. ${ }^{40}$

El acuerdo, además de ser ya fruto de la nueva táctica de "oportunismo creativo", evidencia el alejamiento de la dirección de las bases sindicales y el manejo de la organización por parte del Grupo Acción, pues once de ellos firmaron el pacto y paradójicamente ninguno ocupaba un puesto en el Comité Central electo en la segunda Convención, realizada en Zacatecas del 28 de mayo al 5 de junio de 1919.

La importancia de este pacto ha sido señalada con justicia por González Casanova, de la siguiente manera:

Ese acuerdo o pacto reforzó las mediaciones constitucionales ya existentes, formales y sociales, e hizo del caudillismo asociado y del obrerismo acaudillado la dialéctica esencial de los procesos políticos e ideológicos. Fue la base de una nueva acción gubernamental y partidaria. ${ }^{41}$

Pronto los líderes de la CROM comenzaron a cumplir lo estipulado. El 21 de diciembre de 1919 se fundó el Partido Laborista Mexicano (PLM), que se encargaría de sostener la candidatura de Obregón. En un largo manifiesto publicado con fecha del 30 de diciembre explicaban las razones que los movieron a entrar en la lucha politica. En primer lugar señalaban la decepción de los obreros y campesinos por la violación sistemática de los principios de la revolución, lo que podría evitarse poniendo esos principios en manos de un hombre "que los haga irradiar sobre las frentes de todas las clases sociales, con todo su cariño, con todo el sentimiento, con toda su voluntad, y con toda la honradez que ellos merecen". Después destacaban su deseo de aportar su contingente en el encauzamiento de la opinión popular.

Y lo hacemos así -decían-, porque estamos seguros de que los trabajadores somos capaces de formarnos por el propio esfuerzo, una personalidad que responda justa y severamente a todas las necesidades propias y nacionales. Y lo hacemos así porque todos los compañeros de la República, convendrán, ante los fracasos que por los políticos de oficio hemos llevado, en que ya no es tiempo de confiar a hombres ajenos a las necesidades de nuestra vida, la resolución de los problemas que sólo nosotros comprendemos.

...

Luego nuestra participación en política -continuaban-, será para trabajar por la formación de un gobierno; si no de tendencia tan avanzada como muchos deseáramos, sí cuando menos un gobierno que adopte una política transaccional que reconociendo la autoridad del mayor número, introduzca reformas que vayan de acuerdo con el avance progresivo que marque la mayor suma de tendencias innovado-

40 Marjorie Ruth Clark, op. cit., p. 64-65.

1 Pablo González Casanova, op. cit., p. 106. 
ras; y además, que cumpla con los principios que fueron la vida de la Revolución, hoy defraudada en su tendencia social, que fue la que llevó a las barricadas del heroismo a muchos obreros y campesinos amantes de la libertad.

Más claro no podía definirse el carácter reformista de los dirigentes cromistas.

En cuanto al programa, este era prácticamente el de la CROM, con algunas adiciones: la lucha por el municipio libre, la independencia de poderes y la igualdad de la mujer.

Pocos días después, el 4 de enero de 1920, Morones oficializó la candidatura de Obregón. Los líderes laboristas habian encontrado al hombre con quien, en virtud de una política transaccional, obtendrían reformas y facilidades para el desarrollo de la organización sindical, así como puestos en el aparato gubernamental. Por lo pronto, tres prominentes miembros del grupo, Morones, Samuel Yúdico y Eduardo Moneda, se integraron al Centro Directivo Obregonista, organismo que coordinaba la campaña electoral.

Durante febrero, marzo y abril, en vísperas del rompimiento entre Sonora y Carranza, la agitación obrera orquestada por la CROM fue importante en el deterioro de la capacidad de control del gobierno carrancista. El 13 de abril se precipitaron los acontecimientos al escapar Obregón de la ciudad de México, a donde había sido llamado para intervenir en un juicio en el que se le acusaba de haberse confabulado con el rebelde Roberto Cejudo contra el gobierno carrancista. En el peliculesco escape de Obregón, saltando de un coche en movimiento en las calles de Orizaba, la participación obrera fue determinante. Un ferrocarrilero, Margarito Ramirez, se encargó de conducirlo hasta Iguala, donde fue recibido por los generales Rómulo Figueroa y Fortunato Maycote. Posteriormente se incorporó Morones al grupo. Desde Chilpancingo, Morones redactó un manifiesto, en el que desconoció al Presidente e incorporó el movimiento obrero al levantamiento de Agua Prieta.

En ese documento, fechado el 20 de abril de 1920, se declaraba que la actitud agresiva del gobierno central contra los gobiernos de Sonora, Zacatecas, Michoacán, contra el propio PLM y en contra de la candidatura de Obregón, impedian el desarrollo del programa del partido; y que, en consecuencia, había llegado el momento en que de acuerdo con las resoluciones respectivas tomadas en la

precipitada Convención de Zacatecas, el Partido Laborista Mexicano, integrado por obreros y campesinos, haga uso de toda la fuerza moral y material de que dispone para defender resueltamente los principios $\mathrm{e}$ intereses de sus miembros en particular y del proletariado en general, $y$, al efecto, el Comité recomienda a sus representados que incontinente se apresten a cooperar en la lucha que han iniciado nuestros hermanos de Sonora, Zacatecas y Guerrero, en defensa de la soberania de los Estados y de la libertad de sufragio.

En esa misma ocasión se precisaba que el Comité Directivo General del Partido seguiría funcionando y representando los intere-

42 El Monitor Republicano, 3 enero 1920, p. 1. 
ses laborales cerca de Obregón y de Adolfo de la Huerta, gobernador de Sonora, y director provisional del movimiento. Finalmente, terminaban haciendo un dramático llamado a los trabajadores de los Estados Unidos, de América Latina, de Europa, Africa y Asia, para que brindaran su ayuda a fin de que el pueblo mexicano no fuera obligado a aceptar un gobierno con el que no estaba de acuerdo. ${ }^{43}$

Esas sin embargo, no eran las únicas justificaciones que tenía el movimiento obrero para romper con Carranza. En un articulo titulado "Por qué luchamos los trabajadores contra Carranza", otro de los líderes del Grupo Acción, Juan Rico, hacia una larga exposición de la actitud antiobrera del Presidente, de la represión a la huelga general de 1916, a los maestros, a las ligas de resistencia de Yucatán, y al Partido Revolucionario Obrero de Tabasco, que había apoyado la candidatura de Carlos Green en contra del candidato oficial Luis Felipe Domínguez. ${ }^{44}$

\section{Conclusiones}

El gobierno constitucional de Venustiano Carranza se caracterizó por imponer una política autoritaria sobre el conjunto de la sociedad, pero particularmente sobre los trabajadores y sus organizaciones. En realidad ello era el complemento obligado de una política económica que hacía descansar la reconstrucción nacional en las espaldas de los trabajadores, aunque sin poder lograr el apoyo pleno de la burguesía.

En esas condiciones en que el Ejecutivo respondía a las demandas de los trabajadores con la represión directa, se dio el tránsito del anarcosindicalismo que rehuía la participación política, a la acción múltiple, cuyo sustento estaba en una política de "oportunismo creativo", que aprovechaba las diferencias existentes entre los revolucionarios vencedores, para buscar alianzas con ellos y lograr por esa vía algunas concesiones para los agremiados. De esta manera, con el triunfo de Obregón, quien representaba una corriente modernizadora del capitalismo, caracterizada por el impulso a la agricultura de exportación, la mecanización del campo, así como el desarrollo industrial y la creación de las instituciones financieras necesarias para generar flujos monetarios intersectoriales, se abrió el paso a la hegemonia de la CROM sobre el movimiento obrero durante más de una década, en colaboración estrecha con los gobiernos emanados del movimiento de Agua Prieta. Así se constituyó una alianza entre el Estado y el movimiento obrero en la que era claro el carácter subordinado del segundo elemento. Las razones de ello deben buscarse en el reconocimiento de la debilidad del movimiento obrero y en la puesta en práctica de una politica de alianzas con fuerzas políticas, es decir, la aplicación del oportunismo creativo, para superarla. Con tal estrategia esperaban lograr algunas reformas que mejoraran las condiciones de vida de sus agremiados, a la vez que posiciones políticas dentro del aparato del Estado, validos de su representatividad formal,

43. Clodoveo Valenzuela, Sonora y Carranza, México, Casa Edit. Renacimiento de G. Sisniega y Hno., 1921, p. 365-366.

${ }^{4+}$ Ibid. , p. $357-359$. 
aunque confiados desde entonces en la negación de cúpula, puesto que, según su peculiar visión, la movilización de masas era inútil sin apoyos fuertes, de fuerzas ajenas al movimiento obrero. 